\title{
Isolation and Characterization of Flavone from the Aerial Parts of Avicennia alba Blume
}

\author{
D.R. KAR*, P. SUDHIR KUMAR, G. GHOSH and P. K. SAHU \\ School of Pharmaceutical Sciences, Siksha 'O' Anusandhan University, \\ Bhubaneswar, Odisha - 751030, India. \\ Corresponding author: E-mail: durgesh176@gmail.com \\ http://dx.doi.org/10.13005/ojc/300242
}

(Received: March 08, 2014; Accepted: April 19, 2014)

\begin{abstract}
The present work deals with the isolation and structure elucidation of new flavones from methanol extract of Avicennia alba aerial parts. Isolation of the compound was carried out by chromatographic techniques, followed by different spectral analytical methods. The spectral data of UV-Vis, FT-IR, ${ }^{1} \mathrm{H}$ NMR, ${ }^{13} \mathrm{C}$ NMR and GC-MS of the isolated compound is in support of presence of flavone nucleus. The compound has been characterized as 2-[3'-(3"(hydroxymethyl)oxiran-2"-yl)-2'-methoxy-4'-(methoxymethyl)phenyl]-4H-chromen-4-one.
\end{abstract}

Key words: Avicennia alba, aerial parts, flavones, spectral characterization.

\section{INTRODUCTION}

Plant-based drugs play an important role in both traditional and modern system of medicine'. Now a day, plant extracts are used in traditional system of medicine and still continue to provide health coverage over $80 \%$ of the world's population in the developing countries ${ }^{2}$. Avicennia alba Blume. (A. alba) is a type of tropical mangrove and classified to the family Avicenniaceae. The plant is distributed in India, Burma, Malacca and Ceylon ${ }^{3}$. The plant is commonly grown in intertidal zones of tropical and sub-tropical area ${ }^{4}$.

It is used for the treatment of several types of diseases such as sexual disorders, scabies, rheumatism, paralysis, asthma and snake-bites and ulcer $^{5}$. The resin of seeds and leaves is used in traditional medicine as contraceptive ${ }^{6}$. Various studies have reported that the extract of Avicennia alba shows broad range of biological activities, such as anti-cancer, anti-inflammatory, anti-microbial, antidiarrhoeal and analgesic ${ }^{7-9}$.

Previous phytochemical studies on the plant have reported in the isolation of steroids, triterpenes, saponins, flavonoids, alkaloids and tannins ${ }^{10}$. Three naphthoquinones and their analogues such as avicequinone-A, avicequinone$B$, avicequinone-C and avicenol-A, avicenol-B, avicenol-C respectively, were isolated from stem bark of Avicennia alba ${ }^{11}$. In our present study, we 
have investigated on the aerial parts of Avicennia alba and reported the isolation and structural elucidation of new the flavone.

\section{MATERIALS AND METHODS}

\section{Plant materials}

The aerial parts of Avicennia alba were collected from Sundarban area, South 24 Parganas, West Bengal, India, in the month of October, 2011 on the basis of Ethnomedicinal uses. The plant was identified \& authenticated by the taxonomist from the botanical survey of India, Botanical Garden, Howrah, West Bengal. A voucher specimen $(\mathrm{CNH} /$ $128 / 2011 /$ TECHII/637) has been deposited in the herbarium of the Department of Pharmacognosy, School of Pharmaceutical Sciences, Siksha O Anusandhan University, Odisha, India.

\section{Extraction and isolation of compound}

The air-dried plant materials $(500 \mathrm{~g})$ of Avicennia alba were coarsely powdered and extracted in a Soxhlet apparatus with methanol for 48 hours. The methanolic extract was concentrated to obtain a dark viscous mass (64 g). A little amount of the extract was screened chemically for determination of different phytoconstituents. The concentrated extract was dissolved in little quantity of methanol and adsorbed on silica gel (60-120 mesh) for preparation of slurry. The slurry was then air-dried and chromatographed over a silica gel (60-120 mesh) column. The column was eluted with $\mathrm{n}$-hexane initially, then eluted with n-hexane-ethyl acetate mixtures of increasing polarity (95:5, 90:10, $80: 20,70: 30,60: 40$ and 50:50). Various fractions were collected separately and matched by TLC to check their homogeneity. The fractions with same $R_{\mathrm{f}}$ values were combined together and crystallized. The compound was then recrystallized with methanol and finally purified by preparative TLC. The isolated compound was subjected to various physical and spectral studies for characterization.

\section{EXPERIMENTAL}

A Soxhlet extractor was used for extraction. The melting point was determined in open capillary tube (Sisco) and is uncorrected. The spectra were recorded with the following instruments, IR: Bruker -FTIR-8400S spectrophotometer using KBr powder;
NMR: ${ }^{1} \mathrm{H}$ NMR and ${ }^{13} \mathrm{C}$ NMR spectra on Bruker DRX500 NMR spectrometer using MeOD as the solvent at $500 \mathrm{MHz}$ and $125 \mathrm{MHz}$ respectively; GC-MS: Shimadzu-Mass spectrophotometer; TLC with silica gel $\mathrm{GF}_{254}$; column chromatography silica gel (60120 mesh, Merck) and elemental analysis: Perkin Elmer-2400 Auto system.

\section{RESULTS}

UV-VIS

$\lambda_{\max }: 228,312 \mathrm{~nm}$

\section{FTIR (KBr) $\mathbf{c m}^{-1}$ study}

The IR absorption spectrum showed absorption peaks at $3154.97(\mathrm{OH}$ str), $1710.56(\mathrm{C}=\mathrm{O}$ str.), 2853.48 ( $\mathrm{CH}_{2}$ str.), 1610.27 (C=C str.), 1468.53, 1175.40 (C-O-C str.), 1092.48(C-O str.).

${ }^{1} \mathrm{HNMR}$ (MeOD, $500 \mathrm{MHz}$ ) study

${ }^{1} \mathrm{HNMR}$ has given signals at $\delta 6.41(1 \mathrm{H}, \mathrm{s}$, $\mathrm{H}-3), 8.19$ (1H, m, ArH-5), 7.47 (1H, m, ArH-6), 7.56 $(1 \mathrm{H}, \mathrm{m}, \mathrm{H}-7), 7.55(1 \mathrm{H}, \mathrm{d}, \mathrm{H}-8), 3.83\left(3 \mathrm{H}, \mathrm{s} . \mathrm{OCH}_{3}-\right.$ $\left.2^{\prime}\right), 6.72\left(1 \mathrm{H}, \mathrm{s}, \mathrm{H}-5^{\prime}\right), 7.12\left(1 \mathrm{H}, \mathrm{s}, \mathrm{H}-6^{\prime}\right), 4.83(2 \mathrm{H}, \mathrm{s}$, $\left.\mathrm{CH}_{2}-4^{\prime}\right), 3.31\left(3 \mathrm{H}, \mathrm{s}, \mathrm{O}-\mathrm{Me}-4^{\prime}\right), 3.86\left(1 \mathrm{H}, \mathrm{d}, \mathrm{H}-2^{\prime \prime}\right)$, 2.85 (1H, d, H-3"), $3.79\left(2 \mathrm{H}, \mathrm{d}, \mathrm{CH}_{2}-3^{\prime \prime}\right), 4.57(1 \mathrm{H}, \mathrm{s}$, $\left.\mathrm{OH}-3^{\prime \prime}\right)$.

${ }^{13} \mathrm{CNMR}\left(\mathrm{CDCl}_{3}, 125 \mathrm{MHz}\right)$ study

${ }^{13} \mathrm{C}$ NMR $\left(\mathrm{CDCl}_{3}\right): \delta 162.76(\mathrm{C}-2), 110.3$

(C-3), 177.85 (C-4), 125.9 (C-5), 123.9 (C-6), 135.1

(C-7), 116.1 (C-8), 156.4 (C-9), 123.8 (C-10), 109.5

(C-1'), 154.6 (C-2'), 128.33 (C-3'), 137.9 (C-4'), 119.54 (C-5'), 124.8 (C-6'), $56.6\left(\mathrm{OCH}_{3}, \mathrm{C}-7^{\prime}\right), 58.9$ $\left(\mathrm{OCH}_{3} \mathrm{C}-4\right.$ '), 56.01 (oxirane, C-2'), 56.51 (oxirane, C-3"), 64.0 (- $\left.\mathrm{CH}_{2} \mathrm{OH}, \mathrm{C}-3^{\prime \prime}\right)$.

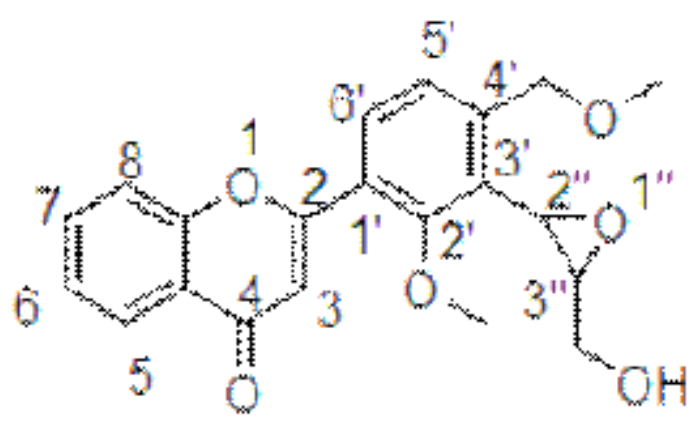

Fig. 1: 2-[3'-(3"-(hydroxymethyl) oxiran-2"-yl)2'-methoxy-4'-(methoxymethyl) phenyl]-4Hchromen-4-one 


\section{DISCUSSION}

The compound (Fig1.) was obtained as a dark yellow compound from n-hexane-ethyl acetate (7:3) eluants with melting point of $215-218^{\circ} \mathrm{C}$. The structure was confirmed by comparison of its spectral data with the corresponding authentic drug or literature based data. The UV absorption $\left(\lambda_{\max }\right.$ :
228, 312nm in $\mathrm{MeOH}$ ) exhibited the characteristic absorption maxima for a flavonoid ${ }^{12}$.

Addition of few drops of cerric ammonium nitrate reagent; it produced red coloration suggesting the presence of alcoholic groups ${ }^{13}$. The FTIR spectroscopic analysis exhibited characteristic broad peak centered at $3154.97 \mathrm{~cm}^{-1}$ that is

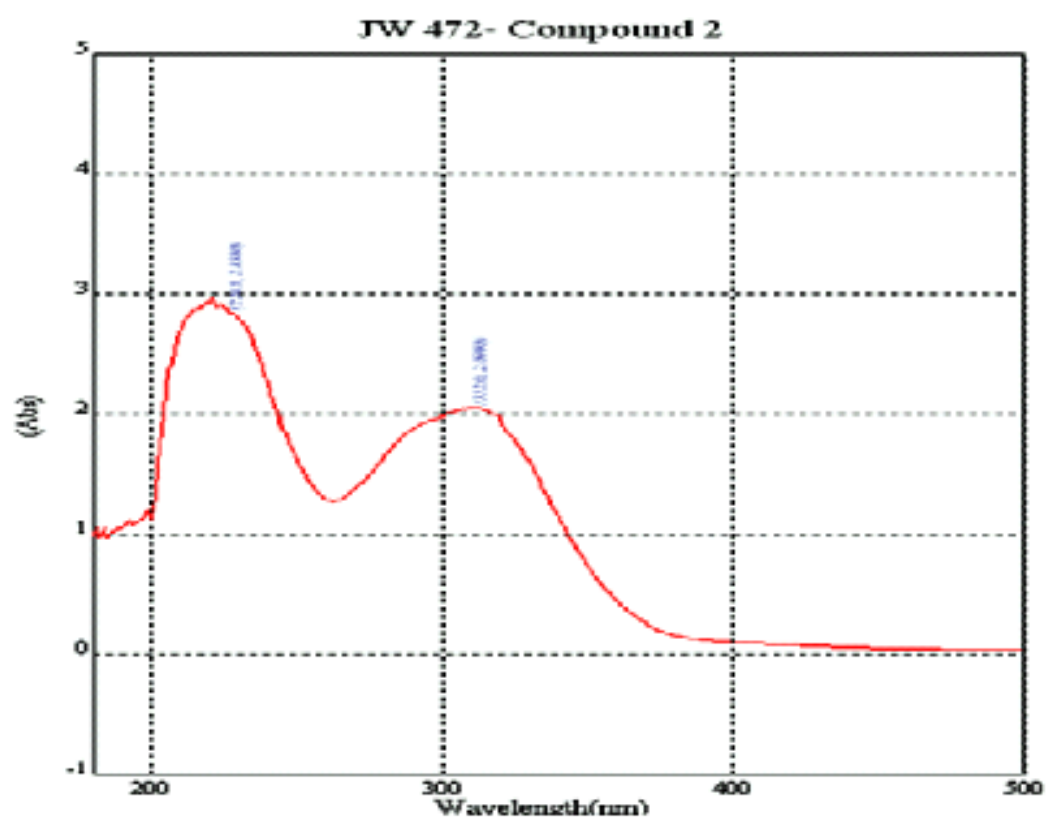

Fig. 2: UV-Vis spectrum of an isolated compound

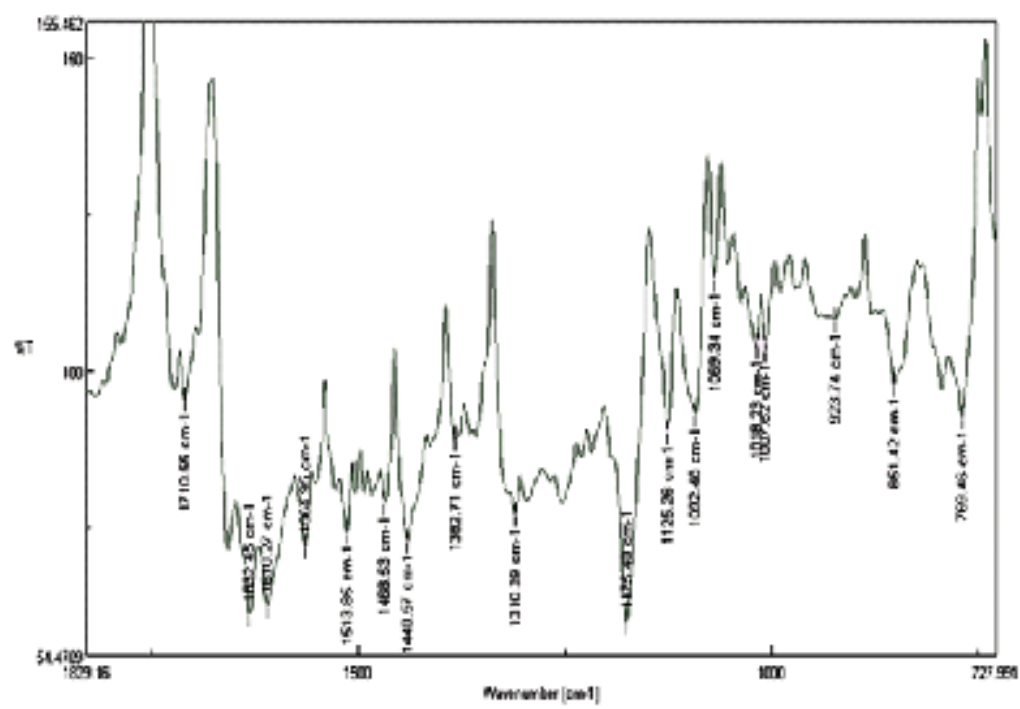

Fig. 3: FTIR spectrum of an isolated compound 
characteristic of $\mathrm{O}-\mathrm{H}$ stretching suggesting the presence of hydroxyl group which was substantiated by chemical identification test. The absorption bands at 2853.48 corresponds to $\mathrm{CH}_{2}$ stretching, at $1710.56 \mathrm{~cm}^{-1}$ as a result of $\mathrm{C}=\mathrm{O}$ stretching, at $1610.27 \mathrm{~cm}^{-1}$ as a result of $\mathrm{CH}=\mathrm{CH}$ stretching, absorption band at $1175.40 \mathrm{~cm}^{-1}$ is due to the presence of C-O-C stretching. The structure of isolated flavone was elucidated by $\mathrm{H}^{1} \mathrm{NMR}$ and ${ }^{13} \mathrm{C}$-NMR techniques as by comparison of spectral data with that of reported earlier ${ }^{14}$

The ${ }^{13} \mathrm{C}$-NMR spectrum of flavone revealed the presence of approximately 21 peaks; twelve aromatic carbon, four active methylene, two methoxy and $\alpha-\beta$ unsaturated hydro carbon atom
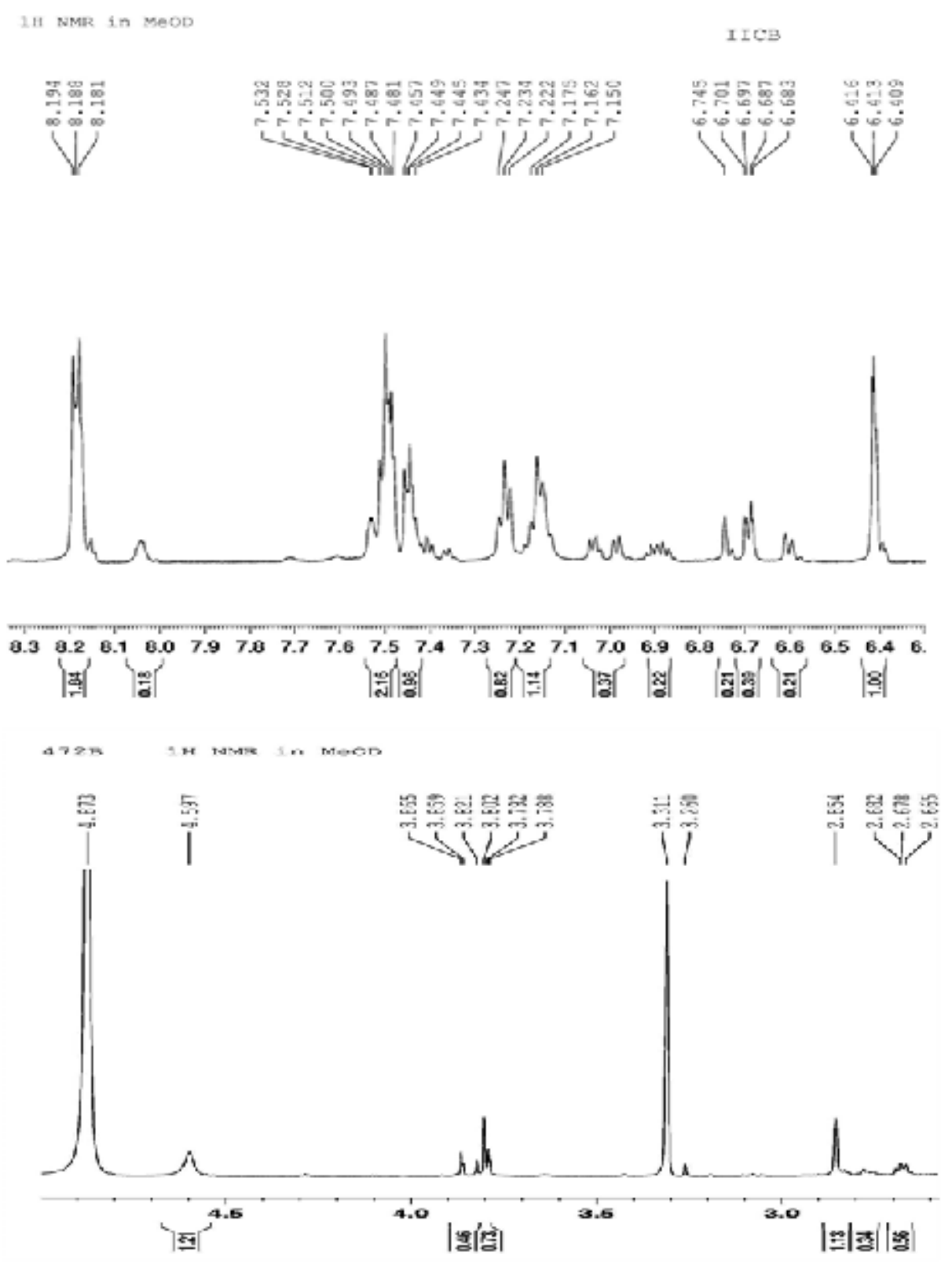

Fig. 4: ${ }^{1} \mathrm{HNMR}$ spectrum of an isolated compound 
attached to ketone system. The presence of aromatic hydrocarbon of the flavone were structurally proved by sharp signal at 125.9, 123.9, 135.1, 116.1, 156.4, 123.8, 109.5, 154.6,115.1,131.9,128.4 and 126.5 which were attributed to the position of $(\mathrm{C}-5),(\mathrm{C}-$
6), (C-7), (C-8), (C-9), (C-10), (C-1'), (C-2'), (C-3'), $\left(\mathrm{C}-4^{\prime}\right),\left(\mathrm{C}-5^{\prime}\right)$ and $\left(\mathrm{C}-6^{\prime}\right)$ respectively. The absorption signal at $64.0 \mathrm{ppm}$, due to the presence of $\mathrm{O}-\mathrm{H}$ attached to the carbon at C-32 2 and also exhibited characteristic broad peak at $3154.97 \mathrm{~cm}^{-1}$ appeared in FTIR spectrum.
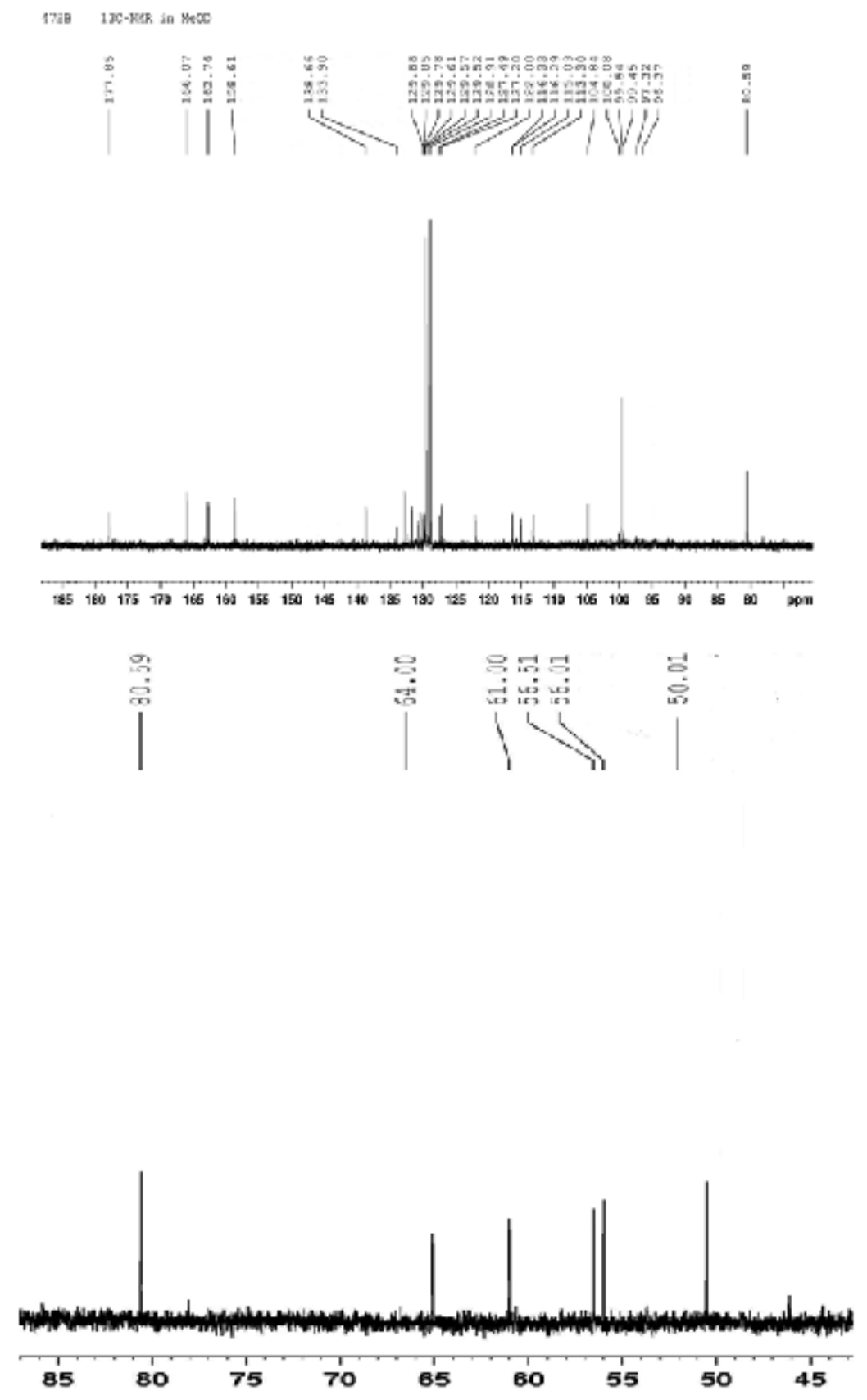

Fig. 5: ${ }^{13} \mathrm{C}$ NMR spectrum of an isolated compound 
The ${ }^{13} \mathrm{C}-\mathrm{NMR}$ showed most recognizable down field sharp signal at $\delta 177.5 \mathrm{ppm}$, corresponds to the presence of ${ }^{3}$ carbonyl group of flavone, which may be assigned to $\mathrm{C}-4$ position. The absorption peaks at $\delta 56.01$ and $56.6 \mathrm{ppm}$ that may correspond to epoxy in form of angular C-O-C atoms at C-2" and C-3" positions. The peaks at $\delta 61.00 \mathrm{ppm}$ showed a sharp signal, assigned at C-4' due to presence of electron donating groups like $\left(-\mathrm{OCH}_{3}\right)$ in this structure. The ${ }^{13} \mathrm{C}$-NMR signals at $\delta 162.6$ and 104.6 were attributed to unsaturation of C-2 and $\mathrm{C}-3$ in isolated flavones structure.

The ${ }^{1} \mathrm{H}$-NMR spectrums displayed sharp aromatic proton signals $\delta \mathrm{H}: 8.18(1 \mathrm{H}, \mathrm{m}, \mathrm{ArH}-5)$, $7.47(1 \mathrm{H}, \mathrm{m}, \mathrm{ArH}-6), 7.56(1 \mathrm{H}, \mathrm{m}, \mathrm{H}-7), 7.55(1 \mathrm{H}, \mathrm{d}$, $\mathrm{H}-8$ ), suggested a flavone skeleton. The singlet proton signal also observed at $\delta 6.54$ which may be contributed due to presence of $\mathrm{H}-3$ cyclic unsaturated ketone system. The singlet proton signal observed at $\delta 3.31 \mathrm{ppm}$ may be attributed due to the presence of the group of methoxy at the position $\mathrm{H}-4$. Two functional ether groups present in same structure were distinguished by $\mathrm{H}^{1} \mathrm{NMR}$ spectra as methoxy and epoxy groups. The epoxy protons signal appeared at $\delta 2.89$ and 3.81 which were assigned to $\mathrm{H}-2^{2}$ "and $\mathrm{H}-3$ " positions which was also supported by IR stretching at $1175.40 \mathrm{~cm}^{-1}$.

GC MS spectroscopy showed a molecular ion $[\mathrm{M}]^{+}$peak at $368.13 \mathrm{~m} / \mathrm{z}$ value corresponding $\left[\mathrm{C}_{21} \mathrm{H}_{20} \mathrm{O}_{6}\right]$ which confirms the proposed molecular formula. The Chemical name of this flavones derivative is 2-(5-(3-(hydroxymethyl) oxiran-2-yl)2-methoxy-4-(methoxymethyl) phenyl)-4Hchromen-4-one and were supported by the molecular weight 368.38 calculated by Rast's procedure. It also showed a series of peaks at 137 , $163,252,271,268,297,337$ and 368 amu corresponding to various fragments. Fragmentation ion peaks at $\mathrm{m} / \mathrm{z} 337$ correspond to the loss of $\mathrm{CH}_{2} \mathrm{OH}$ (M-31) group from the C-3" position of the epoxy substituent of parent molecule. The next fragment ion peak at $\mathrm{m} / \mathrm{z} 297(\mathrm{M}-40$ ) corresponds to the removal of epoxy ethane from the C-5' of the parent molecule. Moreover, the two signals exhibited at $\mathrm{m} / \mathrm{z} 271$ and 268, from which one should be attributed either due to the loss of -

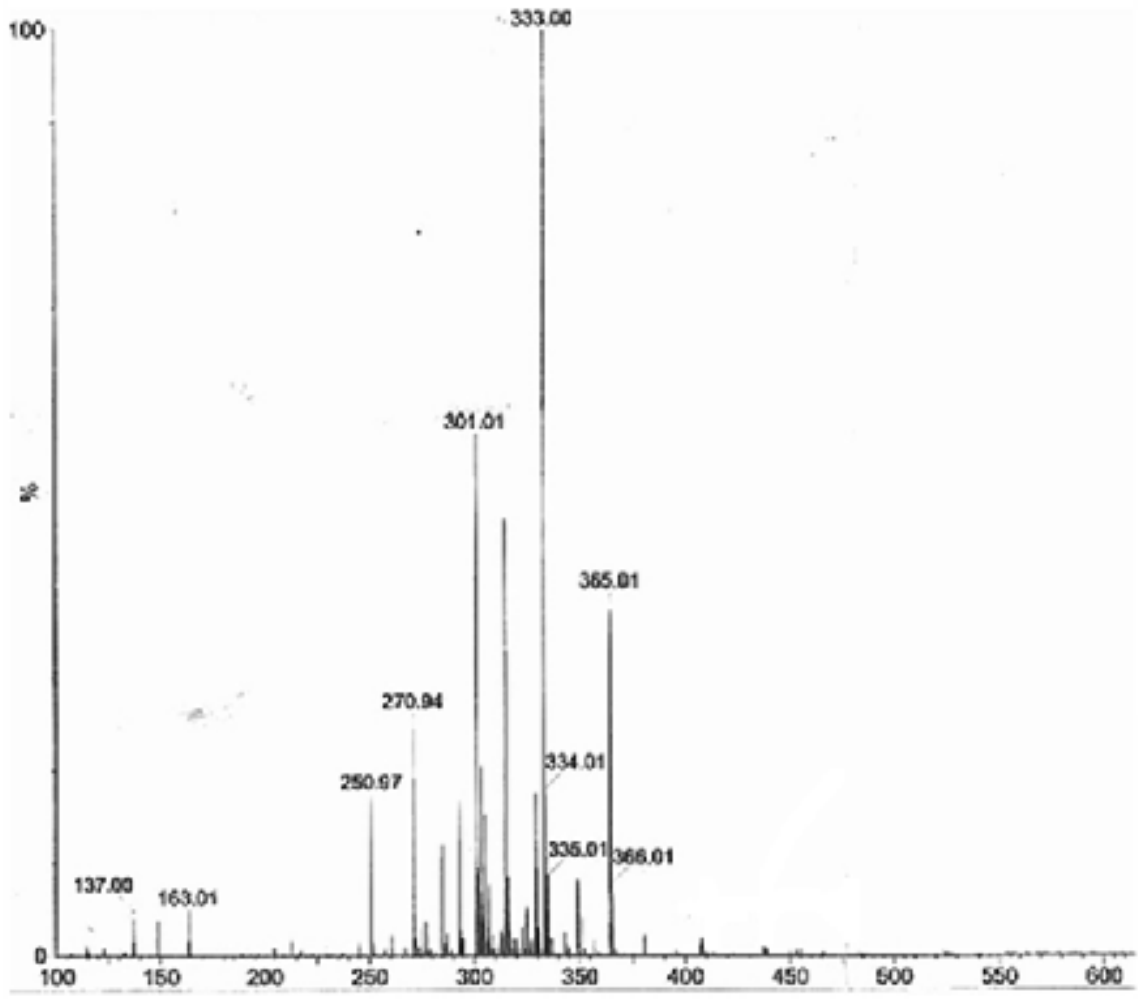

Fig. 6: GC-MS spectrum of an isolated compound 
$\mathrm{CH}_{2} \mathrm{OCH}_{3}$ moiety from the 4'-carbon atom position or attribute the de-methoxylated fragment ion (M31 ) from the $2^{\prime}$-carbon atom position peak. The fragment signals at $\mathrm{m} / \mathrm{z} 252$ appeared due to an equatorial cleavage of isolated flavones structure.

\section{CONCLUSION}

Hence from the above discussion, it was concluded that the isolated molecule contains flavone moiety attached to substituted hydroxyl methyl oxirane at C-5' position and methoxy methyl at the C-4' position. The reported experimental results and ${ }^{13} \mathrm{C}-\mathrm{NMR},{ }^{1} \mathrm{H}-\mathrm{NMR}$ and the Mass spectra reported in the present study led us to formulate the molecular formula of the compound as $\mathrm{C}_{21} \mathrm{H}_{20} \mathrm{O}_{6}$, bearing the IUPAC nomenclature 2-[3'-(3"(hydroxymethyl)oxiran-2"'-yl)-2'-methoxy-4'(methoxymethyl)phenyl]-4H-chromen-4-one.

\section{REFERENCES}

1. Das, P. K., Goswami, S., Chinniah,A., Panda, N., Banerjee, S., Sahu, N. P and Achari, B. J.Ethnopharmacol., 2007; 110: 189-199.

2. Sharma, A.K., Gangwar, M., Tilak, R., Nath, G., Sinha, A.S.K., Tripathi Y.B and Kumar, D. Pharmacog. Journal, 2012; 4(30): 34-40.

3. Rahman, M.A., Biswas, S., Bala, V., Shill, A.K and Bose U. Pharmacologyonline, 2011; 1 : 492-500.

4. Qureshi, R and Bhatti, G.R. Pak. J. Bot., 2008; 40: 979-992.

5. The wealth of India, Raw Materials, C.S.I.R. New Delhi, India, Vol-I: A, 1985; 502-503.

6. Bandaranayake, W.M. Mangroves and Salt Marshes, 1998; 2: 133-148.

7. Ross, S.A., Megalla, S.E., Bisby, D.W and Awad A.H. Fitoterpia, 1980; 5: 303-308.
8. Itoigawaa, M., Itoa, C., Hugh, T.W and MasatoOkudad T. Cancer Letters, 2001; 174 : 135-139.

9. Rahman, M.A., Bala, S. V., Shill A. K and Bose U. Pharmacologyonline, 2011; 1: 492-500.

10. Bandaranayake, W.M. Curr. Topic. Phytochem., 1995; 14: 69-78.

11. Ito, C., Katsuno, S., Kondo, Y., Hugh, T., Tan, T and Furukawa H. Chem. Pharm. Bull., 2000; 48: 339-343.

12. Fu, M.Q., Feng, S.X., Zhang, N.L., Zhou, X.J and Huang, H.J. Helv. Chim. Acta., 2012; 95: 598-605.

13. Selvaraj, S.J., Alphonse, I and Britto, S.J. Indian. J. Chem., 2008; 47: 942-94.

14. Kupeli, E \& Yesilada, E. J. Ethnopharmacol., 2007; 112: 524-530. 